\title{
SCHEDULING PROBLEMS WITH A COMMON DUE WINDOW ASSIGNMENT: A SURVEY
}

\author{
ADAM JANIAK，TOMASZ KWIATKOWSKI，MACIEJ LICHTENSTEIN
}

\author{
Institute of Computer Engineering, Control and Robotics \\ Wrocław University of Technology, Janiszewskiego 11/17, 50-372 Wrocław, Poland \\ e-mail: \{adam.janiak, tomasz.kwiatkowski, maciej.lichtenstein\} @pwr.wroc.pl
}

\begin{abstract}
In this article a survey of studies on scheduling problems with a common due window assignment and earliness/tardiness penalty functions is presented. A due window is a generalization of the classical due date and describes a time interval in which a job should be finished. If a job is completed before or after the due window, it incurs an earliness or a tardiness penalty, respectively. In this survey we separately analyse the classical models with job-independent and job-dependent earliness/tardiness penalty functions and some other more complicated models. We describe the computational complexity of the problems and the main features of the approaches developed to solve them. Particular attention is paid to practical applications of the analysed models. As turns out, some complicated models combining classical scheduling problems with, e.g., learning and aging effects have no reasonable practical justification in the literature.
\end{abstract}

Keywords: scheduling, due window assignment, earliness/tardiness, practical example.

\section{Introduction}

Decision making is a very complex and widely applicable process. It is often discussed in terms of various technical applications, staring from vehicle control (Gáspár et $a l ., 2012)$ to resource allocation in computational grids (Kołodziej and Xhafa, 2011). In manufacturing systems one of the most crucial decisions that has to be made is determining the production schedule. The international competitive pressure resulting from the globalisation process and the everchanging customer demand forced companies to reevaluate their strategies. Only enterprises that are flexible and responsive in serving customers are able to succeed on the global market.

In order to obtain higher quality products and services, many industries have made substantial progress in shortening their execution lead times through the adoption of the Just-In-Time (JIT) philosophy (Gunn, 1992). As with any inventory system, the JIT system's main objective is to ensure that required material is available exactly when it is needed, while maintaining the inventory at the lowest possible level and eliminating such waste components like overproduction, waiting time, transportation, unnecessary processing, inventory and defective products (Kramer and Lee, 1993). Therefore, it is important that management systems and scheduling theory contribute to the realization of JIT in a manufacturing environment.

Usually, JIT scheduling models assume the existence of job due dates and discourage early as well as tardy jobs. If a job is completed before its due date, it implies an earliness penalty such as holding cost. On the other hand, job finished after its due date implies tardiness costs such as late charges, express delivery, or loss of sales. For earlier surveys of problems with due date, see those by Baker and Scudder (1990), Gordon et al. (2002), as well as Lauff and Werner (2004). Good customer service means finishing jobs (or orders) as close as possible to their due dates. In practice, a "fuzzy" due date can be observed, as a compromise between the customers' expectations and the production capabilities of the manufacturers. The supply contract between the supplier and the customer often specifies a time interval in which the job is to be finished. The time interval is called the due window of a job, and the left end and the right end of the window are called the starting time and the finishing time of the due window, respectively. If the job is completed within the due window, then it is considered to be on time and will not incur any penalty. If a job is finished earlier than the starting time of its due window, then it has to be stored as an inventory, which results in an earliness penalty. On the other hand, if a job is finished later than the 
finishing time of its due window, then it incurs a tardiness penalty as stated in the contract. It is clear that a wide due window increases the suppliers' production and delivery flexibility. However, a large due window and delayed job completion reduce the suppliers' competitiveness and customer service level.

In the scientific literature there can be found many examples of practical problems that can be considered a scheduling problem with a due window assignment (Koulamas, 1996; Kramer and Lee, 1993; Lee, 1991; Wu and Lai, 2007). For instance, consider a manufacturer with a limited storage area that produces on demand, e.g., located in a city centre. Such a manufacturer needs to rent a storage area nearby, which is very expensive, or transport the produced goods to other warehouses outside the city centre. The lease of a remote storage area is much cheaper than a city centre lease but implies additional transportation costs. In order to reduce the costs of transporting the produced goods to the customer, the majority of the order is transported to the client using a chosen (most effective) means of mass transit, e.g., train or truck. Until the delivery is made, the products are stored in the warehouses. The goods that have been produced after the delivery of the main part of the order have to be transported to the customer using other (more expensive) means of transport, e.g., a courier.

In the case of a large order, the manufacturer has to prepare a proper production schedule, decide for how long to rent the additional, much more expensive, storage area close to the factory, and at which point to start the delivery of the main part of the order to the customer in order to minimize the costs of transport and storage. This situation can be transformed into a scheduling problem with a common due window assignment as follows. The end of the common due window is the moment of the delivery of the main part of the order to the client, whereas the due window size is the lease time of the warehouse close to the factory. The costs of renting and transporting goods produced before the lease of the warehouse to other remote storage area are the earliness penalties, while the costs of the transport of the products manufactured after the main delivery had been made (using other, more expensive means of transport) are the tardiness penalties (Winczaszek, 2006).

In the paper we survey all scheduling problems with a common due window assignment that appeared in the scientific literature. Apart from the classical scheduling problems with a common due window assignment, we also consider more complicated models that combine the above mentioned classical ones with changeable job processing times, maintenance activities, deteriorating, learning and aging effects. We concentrate mainly on the computational complexity results of the problems considered and the proposed solution algorithms.

The next section is devoted to the commonly used notation of the problems in question. In Sections 3 and 4 we present the results obtained for the classical models with job-independent and job-dependent earliness/tardiness penalty functions, respectively. Section 5 concerns some other scheduling problems with a common due window assignment combined with mathematically more complicated models of job processing times. Some conclusions are given in Section 7

\section{Problem notation}

This section presents the problem notation which is used in the article. We investigate problems of scheduling $n$ jobs $\left(J_{1}, J_{2}, \ldots, J_{n}\right)$ on $m$ parallel machines $\left(M_{1}, M_{2}\right.$, $\ldots, M_{m}$ ) to minimize a given criterion. It is assumed that a machine can process at most one job at a time, and all jobs are ready for processing at time $t=0$. Each job is characterized by its processing time $p_{j}$ and a given set of weights, e.g., $\alpha_{j}, \beta_{j}, \gamma, \delta, \theta$.

Let us define the following:

- $e_{j}$ : the beginning of the due window (earliest due date) of job $J_{j}$;

- $d_{j}$ : the end of the due window (latest due date) of job $J_{j}$;

- $D_{j}=d_{j}-e_{j}$ : the size of the due window;

- $S_{j}$ : the starting time of job $J_{j}$;

- $C_{j}$ : the completion time of job $J_{j}$;

- $E_{j}=\max \left\{e_{j}-C_{j}, 0\right\}$ : the earliness of job $J_{j}$;

- $T_{j}=\max \left\{C_{j}-d_{j}, 0\right\}:$ the tardiness of job $J_{j}$;

- $\langle e, d\rangle$ : the common due window, i.e., $e_{j}=e$ and $d_{j}=d$ for each job $J_{j}$, where $e$ and $d$ are to be assigned in an optimization process. The beginning and end of the due window are usually real numbers, unless stated otherwise.

The above notation appears in the second and the third field of the three-field notation introduced by Graham et al. (1979). The machine environment is described in the first field of this notation.

\section{Classical models with job-independent earliness/tardiness penalty functions}

In this section we analyze the problems with the common due window assignment and job-independent earliness and tardiness penalty functions. We will start with the sum type criteria. 
3.1. Sum type criteria. The problem in which both the beginning and the size of the due window are decision variable,

$$
1|\langle e, e+D\rangle| \sum\left(\alpha E_{j}+\beta T_{j}\right),
$$

was investigated by Kramer and Lee (1993) as well as Weng and Ventura (1996). The authors constructed $O(n \log n)$ time optimal algorithms to solve the problem.

Observe that the penalty function of the above mentioned scheduling problem does not take into account the size of the due window nor its location. Adding the due window size and location penalties makes the problems more realistic. The following problems:

$$
\begin{array}{r}
1|\langle e, d\rangle| \sum\left(\alpha E_{j}+\beta T_{j}\right)+\gamma(d-e)+\delta e, \\
1|\langle e, d\rangle| \sum\left(\alpha E_{j}+\beta T_{j}\right)+\gamma(d-e)
\end{array}
$$

were studied by Liman et al. (1998) as well as Janiak and Marek (2009; 2004), respectively. Optimal $O(n \log n)$ time algorithms were constructed for these problems.

The problem in a parallel identical machine environment was considered by Janiak and Winczaszek (2005a):

$$
P|\langle e, d\rangle| \sum\left(\alpha E_{j}+\beta T_{j}\right)+\gamma(d-e) .
$$

It was demonstrated that the problem is strongly NP-hard and an optimal algorithm based on dynamic programming method with time complexity $O\left(m n^{m}\left(\sum p_{j}\right)^{m-1}\right)$ was provided.

Even with unit earliness/tardiness penalty weights the problem still remains strongly NP-hard. Janiak et al. (2007) along with Janiak and Marek (2003) investigated the following problem:

$$
P|\langle e, d\rangle| \sum\left(E_{j}+T_{j}\right)+\gamma(d-e) .
$$

The authors showed that it is equivalent to the problem $P \| C_{\max }$, in the sense that an optimal solution of one of them can be derived from an optimal solution of the other one in polynomial time. Hence, the analysed problem is strongly NP-hard, since $P \| C_{\max }$ is strongly NP-hard (Garey and Johnson, 1978). A heuristic algorithm with the worst case ratio equal to $\frac{4}{3}-\frac{1}{3 m}$ and an optimal algorithm based on dynamic programming method with computational complexity $O\left(n\left(\sum p_{j}\right)^{m}\right)$ can be provided.

Janiak and Winczaszek (2003) investigated a problem in which the beginning and the size of the due window are decision variables but the due window size is constrained from above and below:

$$
\begin{aligned}
1\left|\langle e, d\rangle, D_{\min } \leq d-e \leq D_{\max }\right| & \\
& \alpha \sum E_{j}+\beta \sum T_{j}+\theta e+f_{W}(d-e),
\end{aligned}
$$

where $f_{W}$ is an arbitrary concave increasing function. The time complexity of the algorithm provided $O(n \log n+$ $\left.\log p_{\max }\right)$. It can be noticed that if $D_{\max } \geq \sum p_{j}$ and $D_{\min }=0$, then in fact the due window size can be freely established and, if $D_{\min }=D_{\max }$, then in fact due window size is given in advance. Thus, this problem is a generalization of the single machine problems described earlier in this section.

A more general problem with non-linear earliness/tardiness penalty functions was studied by Janiak and Winczaszek (2004):

$$
\begin{aligned}
& 1\left|\langle e, d\rangle, D_{\min } \leq d-e \leq D_{\max }\right| \\
& \sum f_{E}\left(E_{j}\right)+\sum f_{T}\left(T_{j}\right)+f_{D}(e)+f_{W}(d-e),
\end{aligned}
$$

where $f_{E}, f_{T}$ and $f_{W}$ are arbitrary nondecreasing functions with $f_{E}(0)=f_{T}(0)=f_{W}(0)=0$. It was shown that the problem is NP-hard and the authors proposed a pseudopolynomial time $O\left(n\left(\sum p_{j}-D_{\text {min }}\right)^{2}\right)$ solution algorithm.

Janiak and Winczaszek (2006) studied further the parallel machine version of the problem

$$
\begin{aligned}
& P\left|\langle e, d\rangle, D_{\min } \leq d-e \leq D_{\max }\right| \\
& \sum f_{E}\left(E_{j}\right)+\sum f_{T}\left(T_{j}\right)+f_{D}(e)+f_{W}(d-e),
\end{aligned}
$$

where $f_{E}, f_{T}$ and $f_{W}$ are arbitrary nondecreasing functions with $f_{E}(0)=f_{T}(0)=f_{W}(0)=0$. It was proven that the problem is strongly NP-hard and an optimal algorithm based on the dynamic programming method with time complexity $O\left(n\left(\sum p_{j}\right)^{3 m-1}\right)$ was provided.

Wu and Wang (1999) analysed a problem in which the due window size is constrained from above and a flowtime penalty is also taken into account:

$$
1\left|\langle e, d\rangle, d-e \leq \min p_{j}\right| \sum\left(\alpha E_{j}+\beta T_{j}+\theta C_{j}\right)+\delta d .
$$

It was shown that the problem is solvable in $O(n \log n)$ time.

Mosheiov and Sarig (2008) extended a classical single machine due window assignment problem to the case of position-dependent processing times:

$$
1\left|\langle e, d\rangle, p_{i j}\right| \sum\left(\alpha E_{j}+\beta T_{j}\right)+\gamma(d-e)+\delta e .
$$

The authors did not restrict the processing time function to be either monotonically increasing (to reflect deterioration) or monotonically decreasing (to reflect learning). They provided an $O\left(n^{3}\right)$ time optimal algorithm.

Mosheiov and Oron (2004) addressed a common due-window assignment problem on parallel identical machines with unit processing time jobs,

$$
P m|\langle e, d\rangle| \sum_{i=1}^{m} \sum_{j=1}^{n_{i}} \alpha E_{i j}+\beta T_{i j}+\gamma e+\delta(d-e) .
$$


The authors showed that the number of candidate values for the optimal due-window starting time and for the optimal due-window completion time is bounded by 2 . It was also proven that the starting time of the first job on each of the machines is either 0 or 1 , thus allowing introduction of a fairly simple, constant-time solution for the problem.

3.2. Min-max type criteria. So far we have discussed only the scheduling problems with minimization of the sum of earliness/tardiness penalties and the due window size and location penalties. Now, we will survey a group of scheduling problems with a common due window assignment concerning the min-max criterion.

Janiak et al. (2007) showed that the single machine problem

$$
1|\langle e, d\rangle| \max \left\{\alpha \max _{j} E_{j}, \beta \max _{j} T_{j}, \gamma(d-e)\right\}
$$

is polynomially solvable. They constructed an $O(n)$ time optimal algorithm to solve the problem.

Mosheiov and Sarig (2009a) studied a similar problem:

$$
1|\langle e, d\rangle| \max \left\{\alpha \max _{j} E_{j}, \beta \max _{j} T_{j}, \gamma e, \delta(d-e)\right\} .
$$

They provided an $O(n)$ time solution algorithm.

Janiak et al. (2007) investigated the following parallel machine problem with the min-max criterion:

$$
P|\langle e, d\rangle| \max \left\{\alpha \max _{j} E_{j}, \beta \max _{j} T_{j}, \gamma(d-e)\right\} .
$$

The authors showed that it is equivalent to the problem $P|\langle e, d\rangle| \sum\left(E_{j}+T_{j}\right)+\gamma(d-e)$, in the sense that an optimal solution of one of them can be derived from an optimal solution of the other one in polynomial time. Therefore, the analysed problem is strongly NP-hard, since $P|\langle e, d\rangle| \sum\left(E_{j}+T_{j}\right)+$ $\gamma(d-e)$ is strongly NP-hard, as we have observed earlier. Each algorithm for the problem $P|\langle e, d\rangle| \sum\left(E_{j}+\right.$ $\left.T_{j}\right)+\gamma(d-e)$ can be adapted to solve the problem $P|\langle e, d\rangle| \max \left\{\alpha \max E_{j}, \beta \max T_{j}, \gamma(d-e)\right\}$.

Mosheiov (2001) considered the following problem:

$$
P|\langle e, d\rangle| \max \left\{\alpha \max _{j} E_{j}, \beta \max _{j} T_{j}, \gamma e, \delta(d-e)\right\} .
$$

He proposed an $O(\max \{n m, n \log n\})$ time asymptotically optimal approximation algorithm. If the job processing times are independent and identically distributed random variables with bounded support, then the absolute error of the solution obtained by this algorithm approaches zero. Moreover, for the special case of the problem with unit processing times of jobs, this algorithm delivers an optimal solution.
A single machine version of the above problem

$$
1|\langle e, d\rangle| \max \left\{\alpha \max _{j} E_{j}, \beta \max _{j} T_{j}, \gamma e, \delta(d-e)\right\},
$$

was proven to be polynomially solvable by Mosheiov and Sarig (2009a), who provided an $O(n)$ time optimal algorithm

\section{Classical models with job-dependent earliness/tardiness penalty functions}

The due window assignment problems with job-dependent penalty functions are much more general and, therefore, might imply wider practical applications. However, they also are much more complex.

Azizoglu and Webster (1997) considered an NP-hard job scheduling problem on a single machine with an unrestricted due window to minimize the total weighted earliness and tardiness cost:

$$
1|\langle e, e+D\rangle| \sum\left(\alpha_{j} E_{j}+\beta_{j} T_{j}\right) .
$$

This model is closely related to the one studied by Kramer and Lee (1993). However, allowing the penalty rates to be job-dependent not only enabled modeling new problems, where the relative importance of jobs with respect to avoiding early or tardy completion can vary, but also affected the problem's complexity. The problem is NP-hard even for the case of an unrestricted common due instance (Hall and Posner, 1991). Kramer and Lee (1993) presented properties that help characterize the form of optimal schedules and defined an efficient method for calculating a lower bound on the optimum cost. The properties and lower bounding method were incorporated into a two-step branch-and-bound algorithm. Computational test results indicate that the algorithm solves efficiently problems with up to 25 jobs.

Limana and Ramaswamy (1994) analysed a single machine scheduling problem to minimize the sum of weighted earliness and a weighted number of tardy jobs given a delivery window:

$$
1|\langle e, e+D\rangle| \sum \alpha_{j} E_{j}+\beta_{j} U_{j} .
$$

The problem was proven to be NP-hard. The authors presented a dynamic programming based solution algorithm $\left(O\left(n^{2} D \sum p_{j}\right)\right)$.

Yeung et al. (2001a) studied a single machine scheduling problem to minimize the weighted number of early and tardy jobs with a common due window. As in previously presented studies, the window size was a given parameter, but the window location was a decision variable and the objective of the problem was to find a schedule that minimizes the weighted number of early and tardy jobs and the due window location penalty:

$$
1|\langle e, e+D\rangle| \sum\left(\alpha_{j} U_{j}+\beta_{j} V_{j}\right)+\gamma e .
$$


The authors showed that the problem is NP-hard in the ordinary sense only and developed a dynamic programming based pseudo-polynomial $O\left(n^{2} p_{\max }(D+\right.$ 1)) algorithm. They also provided polynomial time algorithms for two special cases:

- an $O(n \log n)$ time algorithm, if $\alpha_{j}=\alpha$ and $\beta_{j}=\beta$ :

$$
1|\langle e, e+D\rangle| \sum\left(\alpha U_{j}+\beta V_{j}\right)+\gamma e,
$$

- and an $O(n)$ time algorithm for the unit job processing times case:

$$
1\left|\langle e, e+D\rangle, p_{j}=1\right| \sum\left(\alpha_{j} U_{j}+\beta_{j} V_{j}\right)+\gamma e .
$$

Yeung et al. (2001b) analysed several single-machine non-preemptive scheduling problems to minimize the sum of weighted earliness-tardiness, a weighted number of early and tardy jobs, common due window location, and flowtime penalties. The authors assumed that the due window location has a tolerance $\left(\hat{d}_{0}\right)$ and the window size is a given parameter. All of the general problems studied in this paper were proved to be NP-hard in the ordinary sense, and pseudo-polynomial time algorithms were developed:

- an $O\left(n^{3}(D+1) p_{\max }^{2}\left(\sum p_{j}+1\right)^{2}\right)$ time, dynamic programming based algorithm, under the assumption that the ratios of the job processing times to the earliness-tardiness weights are agreeable:

$$
\begin{aligned}
1 \mid\langle e, e+D\rangle, p_{i} / \alpha_{i}^{\prime} \geq & p_{k} / \alpha_{k}^{\prime} \\
\Leftrightarrow p_{i} / \beta_{i}^{\prime} \geq p_{k} / \beta_{k}^{\prime} \mid \sum & \left(\alpha_{j}^{\prime} E_{j}+\beta_{j}^{\prime} T_{j}+\alpha_{j} U_{j}+\beta_{j} V_{j}\right) \\
& +\gamma \max \left\{0, d-\hat{d}_{0}\right\}, \quad(22)
\end{aligned}
$$

- an $O\left(n^{3}(D+1)\left(\sum p_{j}+1\right) p_{\max }^{2}\left(\sum p_{j}-D+1\right)^{2}\right)$ algorithm for the problem, in which the flowtime is included in the objective function:

$$
\begin{array}{r}
1|\langle e, e+D\rangle| \sum\left(\alpha_{j} U_{j}+\beta_{j} V_{j}+\theta_{j} C_{j}\right) \\
+\gamma \max \left\{0, d-\hat{d}_{0}\right\},
\end{array}
$$

- an $O\left(n^{2}(D+1)\left(\sum p_{j}+1\right)\left(\sum p_{j}-p_{\min }+1\right)^{2} p_{\max }\right)$ algorithm, if zero tolerance $\left(\hat{d}_{0}=0\right)$ for the due window is assumed:

$$
1|\langle e, e+D\rangle| \sum\left(\alpha_{j} U_{j}+\beta_{j} V_{j}+\theta_{j} C_{j}\right)+\gamma d,
$$

- and a polynomial $O(n \log n)$ time algorithm, for a job-independent penalty ratios:

$$
1|\langle e, e+D\rangle| \sum\left(\alpha^{\prime} E_{j}+\beta^{\prime} T_{j}+\alpha U_{j}+\beta V_{j}\right)+\gamma d .
$$

Janiak and Winczaszek (2005b) proved NP-hardness of the following problem:

$$
\begin{aligned}
& 1 \mid\langle e, d\rangle, D_{\min } \leq d-e \leq D_{\max } \mid \\
& \sum \alpha_{j} E_{j}+\sum \beta_{j} T_{j}+\gamma(d-e),
\end{aligned}
$$

where the due window size is bounded to be within the interval $\left[D_{\min }, D_{\max }\right]$, and investigated the following special cases:

- under the assumption that the ratios of the job processing times to the earliness/tardiness weights are agreeable, the problem

$$
\begin{array}{r}
1 \mid\langle e, d\rangle, D_{\min } \leq d-e \leq D_{\max }, \\
p_{i} / \alpha_{i}<p_{j} / \alpha_{j} \Leftrightarrow p_{i} / \beta_{i}<p_{j} / \beta_{j} \mid \\
\sum \alpha_{j} E_{j}+\sum \beta_{j} T_{j}+\gamma(d-e)
\end{array}
$$

remains NP-hard and is solvable in pseudopolynomial time $O\left(n\left(\sum p_{j}\right)^{2}\right)$;

- even without the due window size restriction, the problem

$$
\begin{array}{r}
1\left|\langle e, d\rangle, p_{i} / \alpha_{i}<p_{j} / \alpha_{j} \Leftrightarrow p_{i} / \beta_{i}<p_{j} / \beta_{j}\right| \\
\sum \alpha_{j} E_{j}+\sum \beta_{j} T_{j}+\gamma(d-e)
\end{array}
$$

still remains NP-hard, although there exists a fully polynomial-time approximation scheme with time complexity $O\left(n^{2} \log ^{3}\left(\max \left\{n, 1 / \epsilon, p_{j}, \alpha_{j}, \beta_{j}, \gamma\right\}\right) / \epsilon^{3}\right) ;$

- the special case with unit processing times of jobs:

$$
\begin{array}{r}
1\left|\langle e, d\rangle, D_{\min } \leq d-e \leq D_{\max }, p_{j}=1\right| \\
\sum \alpha_{j} E_{j}+\sum \beta_{j} T_{j}+\gamma(d-e)
\end{array}
$$

is polynomially solvable in $O\left(n^{3}\right)$ time.

Mosheiov and Sarig (2011) showed that the parallel machine problem with unit job processing times:

$$
P\left|\langle e, d\rangle, p_{j}=1\right| \sum \alpha_{j} E_{j}+\sum \beta_{j} T_{j}+\gamma(d-e)
$$

is polynomially solvable in $O\left(n^{4}\right)$ time.

Mosheiov and Sarig (2010) studied the following problems:

$$
\begin{array}{r}
1|\langle e, d\rangle| \max _{j}\left\{\alpha_{j} E_{j}+\beta_{j} T_{j}+\gamma e+\delta(d-e)\right\}, \\
P m|\langle e, d\rangle| \max _{j}\left\{\alpha_{j} E_{j}+\beta_{j} T_{j}+\gamma e+\delta(d-e)\right\}, \\
F m|\langle e, d\rangle| \max _{j}\left\{\alpha_{j} E_{j}+\beta_{j} T_{j}+\gamma e+\delta(d-e)\right\} .
\end{array}
$$

They showed that for a given job sequence the optimal due window size and location can be found in polynomial time by solving linear programs. 


\section{Other models}

In this section we analyse the models of problems with a common due window assignment extended to such additional complicated situations as changeable job processing times, deteriorating jobs, learning and aging effects, maintenance activities, and so on.

The learning effect is a phenomenon of improving production efficiency during a long time learning process of workers. The aging effect is a process opposite to the learning one, i.e., the workers get tired during the long time production process and their efficiency decreases. The concept of the learning effect was introduced to scheduling theory by Meilijson and Tamir (1984) as well as Dondeti and Mohanty (1998).

Liman et al. (1997) examined a problem with a common due window assignment and changeable job processing times:

$$
\begin{aligned}
& 1\left|\langle e, d\rangle ; p_{j}=p_{j}^{\prime}-x_{j}\right| \\
& \sum\left(\alpha E_{j}+\beta T_{j}+G_{j} x_{j}\right)+\delta e+\gamma(d-e),
\end{aligned}
$$

where $p_{j}$ is the normal processing time, $p_{j}^{\prime}$ is minimum processing time, while $x_{j}$ is the amount of reduction in processing time $\left(0 \leq x_{j} \leq p_{j}-p_{j}^{\prime}\right)$ and $G_{j} x_{j}$ is the cost of shortening the job. The problem considered is solvable in $O\left(n^{3}\right)$ by transformation to the assignment problem.

Wang and Wang (2011) considered a single machine deteriorating jobs scheduling problem with a common due window assignment and the learning effect:

$$
\begin{aligned}
1 \mid\langle e, d\rangle, p_{j}= & \left(a_{j}+b t\right) r^{\alpha} \mid \\
& \sum\left(\alpha E_{j}+\beta T_{j}\right)+\gamma e+\delta(d-e) .
\end{aligned}
$$

The current processing time of job $J_{j}$ scheduled at position $r$ in a sequence is given by $p_{j}=\left(a_{j}+b t\right) r^{\alpha}$, where $t>0$ is the starting time for job $J_{j}, a \leq 0$ is the learning index and $b$ is the deterioration rate, which is common for all jobs. An $O(n \log n)$ time optimal solution algorithm was proposed.

Yang (2010) studied a very similar problem with both start-time dependent learning and position dependent aging effects:

$$
\begin{aligned}
& 1 \mid\langle e, d\rangle, p_{j r}=\left(p_{j}-a t\right) r^{b} \mid \\
& \sum\left(\alpha E_{j}+\beta T_{j}\right)+\gamma e+\delta(d-e),
\end{aligned}
$$

where $p_{j r}=\left(p_{j}-a t\right) r^{b}$ is the current processing time of job $J_{j}$ started at time $t$ and scheduled in the $r$-th position in a sequence, $a>0$ is a common learning rate and $b \geq 0$ is the aging factor. In this model the job processing time consists of two parts. One part is a decreasing start-time dependent function and the other part is an increasing position-dependent function. An $O(n \log n)$ time optimal algorithm was provided.
Cheng et al. (2010) examined another common due window assignment scheduling problem,

$$
\begin{array}{r}
1\left|\langle e, d\rangle, p_{j}=a_{j}+b S_{j}\right| \\
\sum\left(\alpha E_{j}+\beta T_{j}\right)+\gamma e+\delta(d-e),
\end{array}
$$

in which the job processing times follow a linear time-dependent deterioration model. Thus, the current processing time of job $J_{j}$ is given by $p_{j}=a_{j}+b S_{j}$, where $a_{j}$ is the normal processing time, $b>0$ is a common deteriorating factor and $S_{j}$ is the starting time of job $J_{j}$. They showed that the problem is polynomially solvable by an $O(n \log n)$ time algorithm.

Mosheiov and Sarig (2009b) introduced some maintenance activities to scheduling problems with a common due window assignment. A maintenance activity is an optional activity that requires a fixed time interval during which the production is stopped, as the machine is turned off. However, after the activity, the machine becomes more efficient, which is reflected in the new shortened job processing times. Mosheiov and Sarig (2009b) studied a problem

$$
1|\langle e, d\rangle, m a| \sum\left(\alpha E_{j}+\beta T_{j}\right)+\gamma e+\delta(d-e),
$$

in which the scheduler has an option to schedule a maintenance activity $(\mathrm{ma}$ ) that lasts a constant $t$ units of time. During this activity no production is performed. The processing time of job $J_{j}$ is denoted by $p_{j}$ if the job is processed prior to the maintenance activity, and $\lambda_{j} p_{j}$ $\left(0<\lambda_{j} \leq 1\right)$ if it is scheduled after. $\lambda_{j}$ is the modifying rate of job $J_{j}$. This model reflects a maintenance break in a production environment during which the machine is stopped and no production is performed. They provided an $O\left(n^{4}\right)$ time solution algorithm.

The duration of the maintenance activity does not have to be constant. Cheng et al. (2010) introduced the following model of the scheduling problem:

$$
\begin{array}{r}
1\left|\langle e, d\rangle, m a, p_{j}=a_{j}+b S_{j}\right| \\
\sum\left(\alpha E_{j}+\beta T_{j}\right)+\gamma e+\delta(d-e),
\end{array}
$$

in which the job processing times follow a linear time-dependent deterioration model. Thus, the current processing time of job $J_{j}\left(p_{j}\right)$ is given by $p_{j}=a_{j}+b S_{j}$, where $a_{j}$ is the normal processing time, $b>0$ is a common deteriorating factor and $S_{j}$ is the starting time for job $J_{j}$. As before, a maintenance activity is allowed to improve production efficiency. But unlike in the previous model, the maintenance activity does not introduce a modifying rate $\lambda_{j}$. At most one maintenance activity is allowed throughout the planning horizon. Maintenance can be performed immediately after the processing of any completed job. However, the position and starting time of the maintenance activity in the production 
schedule are unknown in advance. It is assumed that the machine will revert to its initial conditions after the maintenance activity and machine deterioration start anew. The duration of the maintenance activity is a linear function of its starting time and is given by $f(t)=\mu+\sigma t$, where $\mu>0$ is the basic maintenance time, $\sigma \geq 0$ is a maintenance factor, and $t$ is the starting time of the maintenance activity. The later the production manager schedules the maintenance break, the worse the condition of the machine and the longer it takes to restore it to its initial state. They proposed an $O\left(n^{2} \log n\right)$ optimal time algorithm.

Yang et al. (2010) also studied the same deteriorating maintenance but with a different job processing time model:

$$
\begin{aligned}
1 \mid\langle e, d\rangle, m a, p_{j r} & =p_{j} r^{a_{j}} \mid \\
\sum\left(\alpha E_{j}+\beta T_{j}\right)+\gamma e+\delta(d-e), &
\end{aligned}
$$

where job $J_{j}$ has a normal processing time $p_{j r}$ and a job-dependent aging factor $a_{j}>0$. If job $J_{j}$ is scheduled in the $r$-th position in a sequence, then its current processing time equals $p_{j r}=p_{j} r^{a_{j}}$. The maintenance activity $(m a)$ is defined as above. An $O\left(n^{4}\right)$ time optimal solution was provided.

Yang (2010) investigated a due window scheduling problem with joint start-time dependent learning and position dependent aging effects under the deteriorating maintenance activity:

$$
\begin{aligned}
1 \mid\langle e, d\rangle, m a, p_{j r} & =\left(p_{j}-a t\right) r^{b} \mid \\
\sum\left(\alpha E_{j}+\beta T_{j}\right)+\gamma e+\delta(d-e), &
\end{aligned}
$$

where $p_{j r}=\left(p_{j}-a t\right) r^{b}$ is the current processing time of job $J_{j}$ started at time $t$ and scheduled in the $r$-th position in a sequence, $a>0$ is a common learning rate and $b \geq 0$ is the aging factor. In this model, each job processing time consists of two parts. One part is a decreasing start-time dependent function and the other part is an increasing position-dependent function. The maintenance activity (ma) is defined as in the work of Mosheiov and Sarig (2009b). An $O\left(n^{2} \log n\right)$ time optimal solution algorithm was provided.

Zhao and Tang (2010) studied a single machine due window assignment problem with deteriorating jobs and a rate-modifying activity:

$$
\begin{aligned}
& 1 \mid\langle e, d\rangle, r m, p_{j}^{A}=p_{j}+b S_{j} \mid \\
& \sum\left(\alpha E_{j}+\beta T_{j}\right)+\gamma e+\delta(d-e) .
\end{aligned}
$$

In this problem the current processing time of a job $\left(p_{j}^{A}\right)$ is a linear function of its starting time $\left(S_{j}\right)$ and the deterioration rates $(b>0)$ are identical for all jobs. The rate-modifying activity $(\mathrm{rm})$ takes $t$ units of time, during which no job can be executed by the machine. The normal processing time of job $J_{j}$ is denoted by $p_{j}$ if the job is processed prior to the rate-modifying activity, and $\lambda_{j} p_{j}$ if it is scheduled afterwards, where $\lambda_{j}>0$ is the modifying rate. If the normal processing time of job $J_{j}$ is $p_{j}\left(\lambda_{j} p_{j}\right)$ the current processing time of job $J_{j}$, if processed from time $S_{j}$, is given by $p_{j}^{A}=p_{j}+b S_{j}\left(p_{j}^{A}=\lambda_{j} p_{j}+b S_{j}\right)$. The authors provided an $O\left(n^{4}\right)$ time solution algorithm.

\section{Discussion and recommendations}

Recently, there has been a lot of studies concerning scheduling with a common due window assignment as well as learning and aging effects. The concept of the learning effect (without any scheduling processes) was first observed during the process of plane production in 1936 and was described by Wright (1936). Obviously, there are several practice examples of the dependency of operation processing times on the learning (or aging) effect but without any scheduling process. Biskup (1999) introduced into scheduling theory a dependency of job processing times on the position of the job in the sequence (i.e., on the number of already processed jobs). The concept of the learning effect was introduced to scheduling theory by Meilijson and Tamir (1984) as well as Dondeti and Mohanty (1998). However, they did not give any reasonable real-life practical example for the model combining the scheduling process with the learning one. Next, several authors (Wang and Xia, 2005; $\mathrm{Wu}, 2005$; Chen et al., 2006; Wang, 2006) considered various scheduling problems with the learning effect even in multimachine flow shop environments without any real-life practical justification.

In this survey, we must emphasize that a combination of scheduling problems and learning or aging effects in one model has no reasonable real-life applications in the literature and that we see no sense in continuing further research considering these scheduling problems from practical (computer engineering, automatic control, technical and economical) point of view, unless such a reasonable real-life example is presented. For a detailed survey of scheduling problems with learning and aging effects, see the work of Janiak et al. (2011), where particular attention was paid to practical applications of the mentioned models.

A separate survey of scheduling problems with maintenance activity with particular attention paid to practical applications of such models should be provided.

\section{Conclusion}

In this article we have presented the state of the art of scheduling problems with a common due window assignment and earliness/tardiness penalty functions. We have reviewed the results concerning the classical models 
Table 1. Computational complexity and solution algorithm results for scheduling problems with a common due window assignment and job-independent earliness/tardiness penalty functions.

\begin{tabular}{|c|c|c|c|}
\hline No. & Problem & Complexity & Algorithms \\
\hline 1 & $1|\langle e, e+D\rangle| \sum\left(\alpha E_{j}+\beta T_{j}\right)$ & $\mathrm{P}$ & $\begin{array}{l}O(n \log n) \text { (Kramer and Lee, 1993; } \\
\text { Weng and Ventura, 1996) }\end{array}$ \\
\hline 2 & $1|\langle e, d\rangle| \sum\left(\alpha E_{j}+\beta T_{j}\right)+\gamma(d-e)+\delta e$ & $\mathrm{P}$ & $O(n \log n)($ Liman et al., 1998) \\
\hline 3 & $1|\langle e, d\rangle| \sum\left(\alpha E_{j}+\beta T_{j}\right)+\gamma(d-e)$ & $\mathrm{P}$ & $\begin{array}{l}O(n \log n)(\text { Janiak et al., 2009; Janiak } \\
\text { and Marek, 2004) }\end{array}$ \\
\hline 4 & $P|\langle e, d\rangle| \sum\left(\alpha E_{j}+\beta T_{j}\right)+\gamma(d-e)$ & s. NP-hard & $\begin{array}{l}O\left(m n^{m}\left(\sum p_{j}\right)^{m-1}\right)(\text { Janiak and Win- } \\
\text { czaszek, 2005a) }\end{array}$ \\
\hline 5 & $P|\langle e, d\rangle| \sum\left(E_{j}+T_{j}\right)+\gamma(d-e)$ & s. NP-hard & $\begin{array}{l}O\left(n\left(\sum p_{j}\right)^{m}\right), \frac{4}{3}-\frac{1}{3 m} \text { (Janiak et al. } \\
2007 ; 2009)\end{array}$ \\
\hline 6 & $1\left|\langle e, d\rangle, d-e \leq \min p_{j}\right|$ & & \\
\hline 7 & $\begin{array}{l}\sum_{\left.1 \mid\langle e, d\rangle, D_{\min } \leq d-\beta T_{j}+\theta C_{j}\right)+\delta d} \leq D_{\max } \mid\end{array}$ & $\mathrm{P}$ & $O(n \log n)($ Wu and Wang, 1999) \\
\hline & $\alpha \sum E_{j}+\beta \sum T_{j}+\theta e+f_{W}(d-e)$ & $\mathrm{P}$ & $\begin{array}{l}O\left(n \log n+\log p_{\max }\right) \quad(\text { Janiak and } \\
\text { Winczaszek, 2003) }\end{array}$ \\
\hline 8 & $\begin{array}{l}1\left|\langle e, d\rangle, D_{\min } \leq d-e \leq D_{\max }\right| \\
\sum f_{E}\left(E_{j}\right)+\sum f_{T}\left(T_{j}\right)+f_{D}(e)+f_{W}(d-e)\end{array}$ & NP-hard & $\begin{array}{l}O\left(n\left(\sum p_{j}-D_{\min }\right)^{2}\right)(\text { Janiak and Win- } \\
\text { czaszek, 2004) }\end{array}$ \\
\hline 9 & $\begin{array}{l}P\left|\langle e, d\rangle, D_{\min } \leq d-e \leq D_{\max }\right| \\
\sum f_{E}\left(E_{j}\right)+\sum f_{T}\left(T_{j}\right)+f_{D}(e)+f_{W}(d-e)\end{array}$ & s. NP-hard & $\begin{array}{l}O\left(n\left(\sum p_{j}\right)^{3 m-1}\right)(\text { Janiak and Wincza- } \\
\text { szek, 2006) }\end{array}$ \\
\hline 10 & $1\left|\langle e, d\rangle, p_{i j}\right| \sum\left(\alpha E_{j}+\beta T_{j}\right)+\gamma(d-e)+\delta e$ & $\mathrm{P}$ & $O\left(n^{3}\right)$ (Mosheiov and Sarig, 2008) \\
\hline 11 & $P|\langle e, d\rangle| \max \left\{\alpha \max _{j} E_{j}, \beta \max _{j} T_{j}, \gamma(d-e)\right\}$ & s. NP-hard & Janiak et al. (2007) \\
\hline 12 & $1|\langle e, d\rangle| \max \left\{\alpha \max _{j} E_{j}, \beta \max _{j} T_{j}, \gamma(d-e)\right\}$ & $\mathrm{P}$ & $O(n)$ (Janiak et al., 2007) \\
\hline 13 & $P|\langle e, d\rangle| \max \left\{\alpha \max _{j} E_{j}, \beta \max _{j} T_{j}, \gamma e, \delta(d-e)\right\}$ & s. NP-hard & heuristic (Mosheiov, 2001) \\
\hline 14 & $1|\langle e, d\rangle| \max \left\{\alpha \max _{j} E_{j}, \beta \max _{j} T_{j}, \gamma e, \delta(d-e)\right\}$ & $\mathrm{P}$ & $O(n)$ (Mosheiov and Sarig, 2009a) \\
\hline 15 & $P m|\langle e, d\rangle| \sum_{i=1}^{m} \sum_{j=1}^{n_{i}} \alpha E_{i j}+\beta T_{i j}+\gamma e+\delta(d-e)$ & $\mathrm{P}$ & (Mosheiov and Oron, 2004) \\
\hline 16 & $1|\langle e, e+D\rangle| \sum\left(\alpha U_{j}+\beta V_{j}\right)+\gamma e$ & $\mathrm{P}$ & $O(n \log n)$ (Yeung et al., 2001a) \\
\hline 17 & $1|\langle e, e+D\rangle| \sum\left(\alpha^{\prime} E_{j}+\beta^{\prime} T_{j}+\alpha U_{j}+\beta V_{j}\right)+\gamma d$ & $\mathrm{P}$ & $O(n \log n)($ Yeung et al., 2001b) \\
\hline
\end{tabular}

of problems with job-independent and job-dependent earliness/tardiness penalties. We have also analysed the research findings related to other mathematically complicated models. Unfortunately, it was stated that some of the last models, e.g., with learning and aging effects have no reasonable practical justification in the literature. Then, there is no sense to continue research considering these scheduling problems from practical (computer engineering, automatic control, technical and economical) point of view, unless such a reasonable real-life example appears.

The concise presentation of the computational complexity and solution algorithm results obtained for the problems presented in this survey are given in Tables 13 (P, NP-hard and s. NP-hard denote class polynomially solvable, NP-hard and strongly NP-hard problems, respectively).

\section{References}

Azizoglu, M. and Webster, S. (1997). Scheduling about an unrestricted common due window with arbitrary earliness/tardiness penalty rates, IIE Transactions 29(11): 1001-1006.

Baker, K.R. and Scudder, G.D. (1990). Sequencing with earliness and tardiness penalties: A review, Operations Research 38(1): 22-36.

Biskup, D. (1999). Single-machine scheduling with learning considerations, European Journal of Operational Research 115(1): 173-178.

Chen, P., Wu, C.-C. and Lee, W.-C. (2006). A bi-criteria two-machine flowshop scheduling problem with a learning effect, Journal of the Operational Research Society 57(9): 1113-1125.

Cheng, T., Yang, S.-J. and Yang, D.-L. (2010). Common due-window assignment and scheduling of linear time-dependent deteriorating jobs and a deteriorating maintenance activity, International Journal of Production Economics 135(1): 154-161, DOI.10.1016/j.ijpe.2010.10.005.

Dondeti, V.R. and Mohanty, B.B. (1998). Impact of learning and fatigue factors on single machine scheduling with penalties for tardy jobs, European Journal of Operational Research 105(3): 509-524. 
Table 2. Computational complexity and solution algorithm results for scheduling problems with a common due window assignment and job-dependent earliness/tardiness penalty functions.

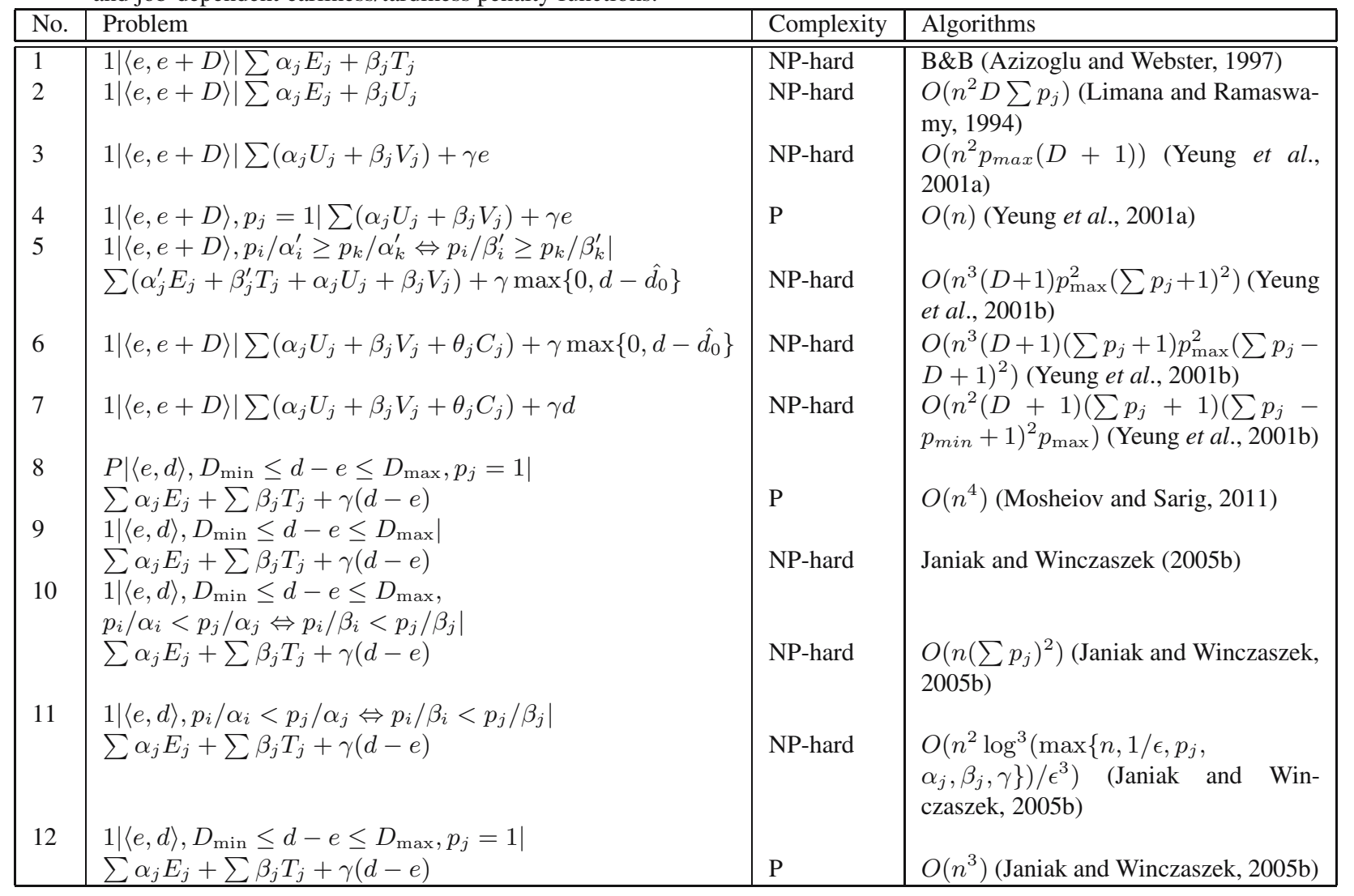

Table 3. Computational complexity and solution algorithm results for scheduling problems with a common due window assignment and some mathematically complicated models of job processing times.

\begin{tabular}{|c|c|c|c|}
\hline No. & Problem & Complexity & Algorithms \\
\hline 1 & $1\left|\langle e, d\rangle ; p_{j}=p_{j}^{\prime}-x_{j}\right|$ & & \\
\hline & $\sum\left(\alpha E_{j}+\beta T_{j}+G_{j} x_{j}\right)+\delta e+\gamma(d-e)$ & $\mathrm{P}$ & $O\left(n^{3}\right)($ Liman et al., 1997) \\
\hline 2 & $1\left|\langle e, d\rangle, p_{j}=\left(a_{j}+b t\right) r^{\alpha}\right|$ & & \\
\hline & $\sum\left(\alpha E_{j}+\beta T_{j}\right)+\gamma e+\delta(d-e)$ & $\mathrm{P}$ & $O(n \log n)($ Wang and Wang, 2011) \\
\hline 3 & $1\left|\langle e, d\rangle, p_{j r}=\left(p_{j}-a t\right) r^{b}\right|$ & & \\
\hline & $\sum\left(\alpha E_{j}+\beta T_{j}\right)+\gamma e+\delta(d-e)$ & $\mathrm{P}$ & $O(n \log n)($ Yang, 2010) \\
\hline 4 & $1\left|\langle e, d\rangle, p_{j}=a_{j}+b S_{j}\right|$ & & \\
\hline & $\sum\left(\alpha E_{j}+\beta T_{j}\right)+\gamma e+\delta(d-e)$ & $\mathrm{P}$ & $O(n \log n)($ Cheng et al., 2010) \\
\hline 5 & $1|\langle e, d\rangle, m a| \sum\left(\alpha E_{j}+\beta T_{j}\right)+\gamma e+\delta(d-e)$ & $\mathrm{P}$ & $O\left(n^{4}\right)$ (Mosheiov and Sarig, 2009b) \\
\hline 6 & $1\left|\langle e, d\rangle, m a, \overline{p_{j r}}=\left(p_{j}-a t\right) r^{b}\right|$ & & \\
\hline & $\sum\left(\alpha E_{j}+\beta T_{j}\right)+\gamma e+\delta(d-e)$ & $\mathrm{P}$ & $O\left(n^{2} \log n\right)($ Yang, 2010) \\
\hline 7 & $1\left|\langle e, d\rangle, m a, p_{j}=a_{j}+b S_{j}\right|$ & & \\
\hline & $\sum\left(\alpha E_{j}+\beta T_{j}\right)+\gamma e+\delta(d-e)$ & $P$ & $O\left(n^{2} \log n\right)($ Cheng et al., 2010) \\
\hline 8 & $\overline{1}\left|\langle e, d\rangle, m a, p_{j r}=p_{j} r^{a_{j}}\right|$ & & \\
\hline & $\sum\left(\alpha E_{j}+\beta T_{j}\right)+\gamma e+\delta(d-e)$ & $\mathrm{P}$ & $O\left(n^{4}\right)($ Yang et al., 2010) \\
\hline 9 & $\begin{array}{l}1\left|\langle e, d\rangle, r m, p_{j}^{A}=p_{j}+b S_{j}\right| \\
\sum\left(\alpha E_{j}+\beta T_{j}\right)+\gamma e+\delta(d-e)\end{array}$ & $\mathrm{P}$ & $O\left(n^{4}\right)($ Zhao and Tang, 2010) \\
\hline
\end{tabular}

Garey, M. and Johnson, D. (1978). Strong NP-completness results: Motivation, examples, and implications, Journal of the ACM 25(3): 499-508.

Gáspár, P., Szabó, Z and Bokor, J. (2012). LPV design of fault-tolerant control for road vehicles, International
Journal of Applied Mathematics and Computer Science 22(1): 173-182, DOI: 10.2478/v10006-012-0013-x.

Gordon, V., Proth, J.-M. and Chu, C. (2002). A survey of the state-of-the-art of common due date assignment and scheduling research, European Journal of Operational Re- 
search 139(1): 1-25.

Graham, R.L., Lawler, E.L., Lenstra, J.K. and Kan, A.H.G. (1979). Optimization and approximation in deterministic sequencing and scheduling: A survey, in P.L. Hammer, E.L. Johnson and B.H. Korte (Eds.), Annals of Discrete Mathematics, Vol. 5, Elsevier, Amsterdam, pp. 287-326.

Gunn, T. (1992). Logistics planning, OR/MS Today 19(1): 16-28.

Hall, N. and Posner, M. (1991). Earliness-tardiness scheduling problems. I: Weighted deviation of completion times about a common due date, Operations Research 39(5): 836-846.

Janiak, A., Janiak, W. and Marek, M. (2009). Single processor scheduling problems with various models of a due window assignment, Bulletin of the Polish Academy of Sciences: Technical Sciences 57(1): 95-101.

Janiak, A., Kovalyov, M. and Marek, M. (2007). Soft due window assignment and scheduling on parallel machines, IEEE Transactions on Systems, Man, and Cybernetics, Part A: Systems and Humans 37(5): 614-620.

Janiak, A., Krysiak, T. and Trela, R. (2011). Scheduling problems with learning and aging effects: A survey, Decision Making in Manufacturing and Services 5(1-2): 19-36.

Janiak, A. and Marek, M. (2003). Scheduling problems with optimal due interval assignment subject to some generalized criteria, in U. Leopold-Wildburger, F. Rendl and G. Wäscher (Eds.), Operations Research Proceedings 2002, Springer-Verlag, Berlin/Heidelberg, pp. 217-222.

Janiak, A. and Marek, M. (2004). Property of symmetry for some single processor scheduling problems with due interval assignment, Systems Science 30(2): 97-107.

Janiak, A. and Winczaszek, M. (2003). An optimal algorithm for a single processor scheduling problem with a common due window, Proceedings of the 9th IEEE International Conference on Methods and Models in Automation and Robotics (MMAR 2003), Międzyzdroje, Poland, pp. 1213-1216 .

Janiak, A. and Winczaszek, M. (2004). Scheduling problem with nonlinear earliness-tardiness penalty functions, in Z. Bubnicki, O. Hryniewicz and J. Weglarz (Eds.), Operation and System Research 2004, Academic Publishing House EXIT, Warsaw, pp. 261-270, (in Polish).

Janiak, A. and Winczaszek, M. (2005a). Optimal algorithm for parallel processor scheduling problem with due window assignment, Proceedings of the 11th IEEE International Conference on Methods and Models in Automation and Robotics, Międzyzdroje, Poland, pp. 1085-1089.

Janiak, A. and Winczaszek, M. (2005b). A single processor scheduling problem with a common due window assignment, in H. Fleuren, D. den Hertog and P. Kort (Eds.), Operations Research, Springer-Verlag, Berlin, pp. 213-220.

Janiak, A. and Winczaszek, M. (2006). Common due window assignment in parallel processor scheduling problem with nonlinear penalty functions, in R. Wyrzykowski, I. Dongarra, N. Meyer and J. Waśniewski (Eds.), Parallel Processing and Applied Mathematics, Springer-Verlag, Berlin, pp. 132-139.
Kołodziej, J. and Xhafa, F. (2011). Modern approaches to modeling user requirements on resource and task allocation in hierarchical computational grids, International Journal of Applied Mathematics and Computer Science 21(2): 243-257, DOI: 10.2478/v10006-011-0018-x.

Koulamas, C. (1996). Single-machine scheduling with time windows and earliness/tardiness penalties, European Journal of Operational Research 91(1): 190-202.

Kramer, F.-J. and Lee, C.-Y. (1993). Common due-window scheduling, Production and Operations Management 2(4): 262-275.

Lauff, V. and Werner, F. (2004). Scheduling with common due date, earliness and tardiness penalties for multimachine problems: A survey, Mathematical and Computer Modelling 40(5-6): 637-655.

Lee, C. (1991). Earliness-tardiness scheduling problems with constant size of due date window, Research Report No. 91-17, Vol. 4, Industrial and Systems Engineering Department, University of Florida, Gainesville, FL, pp. 262-275.

Liman, S.D., Panwalkar, S.S. and Thongmee, S. (1997). A single machine scheduling problem with common due window and controllable processing times, Annals of Operations Research 70: 145-154.

Liman, S.D., Panwalkar, S.S. and Thongmee, S. (1998) Common due window size and location determination in a single machine scheduling problem, Journal of the Operational Research Society 49(9): 1007-1010.

Limana, S. and Ramaswamy, S. (1994). Earliness-tardiness scheduling problems with a common delivery window, Operations Research Letters 15(4): 195-203.

Meilijson, I. and Tamir, A. (1984). Minimizing flow time on parallel identical processors with variable unit processing time, Operations Research 32(2): 440-448.

Mosheiov, G. (2001). A due-window determination in minmax scheduling problems, INFOR 39(1): 107-123.

Mosheiov, G. and Oron, D. (2004). Due-window assignment with unit processing-time jobs, Naval Research Logistics 51(7): 1005-1017.

Mosheiov, G. and Sarig, A. (2008). A due-window assignment problem with position-dependent processing times, Journal of the Operational Research Society 59(7): 997-1003.

Mosheiov, G. and Sarig, A. (2009a). Minmax scheduling problems with a common due-window, Computers \& Operations Research 36(6): 1886-1892.

Mosheiov, G. and Sarig, A. (2009b). Scheduling a maintenance activity and due-window assignment on a single machine, Computers \& Operations Research 36(9): 2541-2545.

Mosheiov, G. and Sarig, A. (2010). Scheduling with a common due-window: Polynomially solvable cases, Information Sciences 180(8): 1492-1505.

Mosheiov, G. and Sarig, A. (2011). A note: A due-window assignment problem on parallel identical machines, Journal of the Operational Research Society 62(1): 238-241. 
Wang, J-B., and Xia, Z.-Q. (2005). Flow-shop scheduling with a learning effect, Journal of the Operational Research Society 56(11): 1325-1330.

Wang, J.-B. (2006). A note on scheduling problems with learning effect and deteriorating jobs, International Journal of Systems Science 37(12): 827-833.

Wang, J.-B. and Wang, C. (2011). Single-machine due-window assignment problem with learning effect and deteriorating jobs, Applied Mathematical Modelling 35(8): 4017-4022.

Weng, M. and Ventura, J. (1996). A note on common due window scheduling, Production and Operations Management 5(2): 194-200.

Winczaszek, M. (2006). Selected Scheduling Problems with Due Window Assignment, Ph.D. thesis, Wrocław University of Technology, Wrocław, (in Polish).

Wright, T.P. (1936). Factors affecting the cost of airplanes, Journal of Aeronautical Science 3(2): 122-128.

Wu, C.-C. (2005). A makespan study of the two-machine flowshop scheduling problem with a learning effect, Journal of Statistics and Management Systems 8(1): 13-25.

$\mathrm{Wu}$, Y. and Lai, K. (2007). A production scheduling strategy with a common due window, Computers \& Industrial Engineering 53(2): 215-221.

Wu, Y. and Wang, D. (1999). Optimal single-machine scheduling about a common due window with earliness/tardiness and additional penalties, International Journal of Systems Sciences 30(12): 1279-1284.

Yang, S.-J. (2010). Single-machine scheduling problems with both start-time dependent learning and position dependent aging effects under deteriorating maintenance consideration, Applied Mathematics and Computation 217(7): 3321-3329.

Yang, S.-J., Yang, D.-L. and Cheng, T. (2010). Single-machine due-window assignment and scheduling with job-dependent aging effects and deteriorating maintenance, Computers \& Operations Research 37(8): 1510-1514.

Yeung, W., Oguz, C. and Cheng, T. (2001a). Minimizing weighted number of early and tardy jobs with a common due window involving location penalty, Annals of Operations Research 108(1-4): 33-54.

Yeung, W., Oguz, C. and Cheng, T. (2001b). Single-machine scheduling with a common due window, Computers \& Operations Research 28(2): 157-175.

Zhao, C. and Tang, H. (2010). A note to due-window assignment and single machine scheduling with deteriorating jobs and a rate-modifying activity, Computers \& Operations Rese$\operatorname{arch}$ 39(6): 1300-1303, DOI:10.1016/j.cor.2010.04.006.

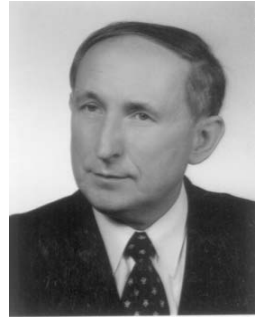

Adam Janiak received the M.Eng. and Ph.D. degrees from the Wrocław University of Technology, Poland, in 1972 and 1977, respectively, and the D.Sc. degree from the Warsaw University of Technology, Poland, in 1992. He obtained the professorial title in 1999. He was a visiting professor at universities in Australia, Canada, Germany, Hong Kong, Israel, New Zealand, Thailand, China, Spain, the US, Greece, Great Britain, Holland, and France. He is currently a full professor of computer science and operations research in industrial engineering areas with the Institute of Computer Engineering, Control and Robotics, Wrocław University of Technology, where he is the head of the Department of Artificial Intelligence and Algorithms Design. He is the author of 7 books and more than 260 papers in edited books, international journals, and conference proceedings, and his h-index (Hirsch index) is $h=22$. His research interests include sequencing and scheduling problems with classical and generalized models of operations in computer and manufacturing systems, resource allocation problems, complexity theory, and the theory of algorithms (physical design automation of very large scale integration). Professor Janiak is an associate editor for IEEE Transactions on Systems, Man, and Cybernetics (Part A), and a member of the editorial boards of Decision Making in Manufacturing and Services, Computer Science, Recent Patents on Computer Science, and Computational Intelligence and Its Applications. He is an academician of the Polish Academy of Sciences, the vice-president of the Computer Science Committee of the Polish Academy of Sciences, and a member of the Computer Science and Informatics (ST6) panel of the Polish National Science Centre. He is an expert of the State Accreditation Committee for the quality of higher education. He has served on program committees for several international conferences on operations research and is a regular reviewer for a number of prestigious journals and conferences.

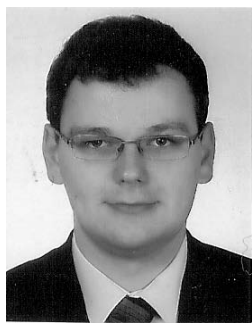

Tomasz Kwiatkowski graduated from the Wrocław University of Technology, Poland, with an M.Eng. degree in control engineering and robotics in 2010, where he is currently working toward his Ph.D. degree in the Institute of Computer Engineering, Control and Robotics. His main research interest concentrates on scheduling and due window assignment problems.

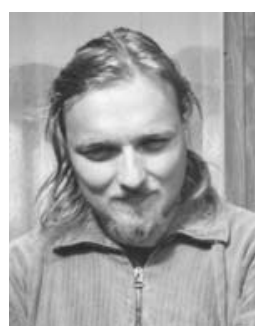

Maciej Lichtenstein received the M.Eng. degree in electronics in 1999 and the Ph.D. degree in automation and robotics in 2003, both from the Wrocław University of Technology, Poland. Since 2003 he has held the position of an assistance professor at the Institute of Computer Engineering, Control and Robotics, Wrocław University of Technology. His main research interests are focused on scheduling problems with various models of operations including setup times, multiprocessor tasks, due window assignment, shop problems, and problems with cost-related criteria. His additional research interests include packing problems and the adaptation of discrete optimization algorithms in such a way that they can utilize the processing power of modern graphics accelerators. 